\title{
Grinding analysis of Indian coal using response surface methodology
}

\author{
Twinkle Singh $^{1} \cdot$ Aishwarya Awasthi $^{1} \cdot$ Pranjal Tripathi $^{1} \cdot$ Shina Gautam ${ }^{2} \cdot$ Alok Gautam $^{2}$
}

Received: 4 December 2015 / Revised: 15 January 2016/ Accepted: 22 February 2016/Published online: 27 June 2016

(C) The Author(s) 2016. This article is published with open access at Springerlink.com

\begin{abstract}
The present work discusses a systematic approach to model grinding parameters of coal in a ball mill. A three level Box-Behnken design combined with response surface methodology using second order model was applied to the experiments done according to the model requirement. Three parameters ball charge (numbers 10-20), coal content (100-200 g) and the grinding time (4-8 $\mathrm{min}$ ) were chosen for the experiments as well as for the modeling work. Coal fineness is defined as the $\mathrm{d}_{80}$ ( $80 \%$ passing size). A quadratic model was developed to show the effect of parameters and their interaction with fineness of the product. Three different sizes $(4,1$ and $0.65 \mathrm{~mm})$ of Indian coal were used. The model equations for each fraction were developed and different sets of experiments were performed. The predicted values of the fineness of coal were in good agreement with the experimental results $\left(R^{2}\right.$ values of $\mathrm{d}_{80}$ varies between 0.97 and 0.99$)$. Fine size of three different coal sizes were obtained with larger ball charge with less grinding time and less solid content. This work represents the efficient use of response surface methodology and the Box-Behnken design use for grinding of Indian coal.
\end{abstract}

Keywords Coal grinding $\cdot$ Ball mill · Grinding time $\cdot$ Response surface methodology

\section{Introduction}

The consumption of solid fossil fuel is gaining importance in world energy production. There has been an increase in studies on coal since it is an alternative to petrol and has a high reserve. The pulverized coal injection is used to obtain high heat capacity and high burning efficiency in thermal reactors and boilers based on coal. For this purpose, coals are ground at a micron size and then sent to boilers to achieve maximum calorific value. Comminution of coal is essential for effective utilization through combustion, carbonization, gasification and/or beneficiation (Prasher 1987). Preheating a coal in an oven has been shown to

Alok Gautam

alokgautam2002@gmail.com

1 Jaypee University of Engineering \& Technology, A-B Road, Raghogarh, Guna, India

2 Shroff S. R. Rotary Institute of Chemical Technology, Ankleshwar, Gujarat, India reduce grind strength, although it is unlikely that this would be an economically viable method, at least not through associated energy requirements (Harrison and Rowson 1997). The grindability of coal is an important practical and economical property to coal handling and utilization aspects. Thus engineering experiments wish to find the grinding conditions under which a certain process reaches its response optimum. The optimum could be either a maximum or a minimum of a function of the design parameters. One of the methodologies is the surface response methodology (Kwak 2005). Grinding media charge ratio in a conventional grinding system is approximately $40 \%$. This leads to a better delivery of the grinding energy (Kincl et al. 2005; Lester et al. 2005; Barranco et al. 2006). Grinding in a ball mill has shown that the ball charge has a significant effect on the product fineness for same specific energy consumption and increases power draws of the mill linearly (Tuzun 1994 and Jankovic 2001). The ball size should be just heavy and large so that the charge should be grinded efficiently. In the present work the ball size is kept constant and these are considered to be 
efficient for the grinding media. In the grinding of Turkish coal and ore, the charge ratio, Bond work index and the ball diameter were taken as the variables in the experiments however, time of grinding is also a significant parameter in the grinding experiments (Aslan and Cebeci 2007; Edadnejad et al. 2013).

The objective of the present work is to establish the optimum conditions for the grinding of an Indian coal. The grinding of coal may depend on several parameters however, in the present study the grinding time, charge content and number of balls in a ball mill are considered as parameters. These three parameters are most important parameters in grinding of coal which were ignored in previous works. According to the requirement of the response surface methodology, experiments were done for three different size fractions of coal. Box-Behnken design to model the experimental results was used.

\section{Materials and methods}

Initially $7-10 \mathrm{~cm}$ size of Indian coal was crushed in a jaw crusher and roll crusher successively to prepare the feed for the ball mill. Three different sizes, $80 \%$ passing of specified screen $\left(\mathrm{d}_{80}\right)$ for grinding test of coal particles were chosen before milling in a ball mill. The $\mathrm{d}_{80}$ sizes of coal particles of feed were 4,1 , and $0.65 \mathrm{~mm}$. After grinding $\mathrm{d}_{80}$ of these sizes were $1.65,0.7,0.25 \mathrm{~mm}$. Grinding tests were performed in a laboratory scale ball mill of $37.5 \mathrm{~cm}$ long and $27 \mathrm{~cm}$ diameter. The size of the balls used were of $2.5 \mathrm{~cm}$ diameter. The rotation speed of the ball mill was kept adequate for the charge to mix and impact together. A proximate analysis of coal is also performed before the actual experiments, Table 1 . The density of the coal used was $1.38 \mathrm{gm} / \mathrm{cm}^{3}$.

\section{Response surface methodology}

Response surface methodology (RSM) is a collection of statistical and mathematical system for the analysis of complex engineering and scientific problems. Using this technique one can evaluate the effect of different important parameters on response.

Table 1 Proximate analysis of a typical Indian coal

\begin{tabular}{ll}
\hline Parameter & Dry basis $(\%)$ \\
\hline Moisture & 6.01 \\
Ash & 39.48 \\
Volatile matter & 18.65 \\
Fixed carbon & 35.6 \\
\hline
\end{tabular}

The design procedure is as follows (Gunaraj and Murugan 1999; Aslan and Cebeci 2007; Edadnejad et al. 2013):

(1) Designing of a series of experiments for adequate and reliable measurement of the surface response of interest.

(2) Developing a mathematical model of the secondorder response surface with the best fittings.

(3) Finding the optimal set of experimental parameters that produce a maximum or minimum value of response.

(4) Representing the direct and interactive effects of process parameters through two and three dimensional (3D) plots.

If all the independent variables are measurable, the response of the surface methodology can be expressed as

$y=f\left(x_{1}, x_{2}, x_{3}, \ldots, x_{n}\right)$

where $y$ is response of the system.

A Box-Behnken design with three levels was utilized to evaluate the effect of parameters on fineness of coal. So these three independent parameters were coded at three levels that is $+1,0$, and -1 with same step size, where +1 represents the maximum value, 0 represents to the center, and -1 represents the minimum value of each parameter, which are considered for analysis. Within the present research framework, the discussion is focused on the effect of number of balls (A), amount of feed charged (B), and grinding time $(\mathrm{C})$ on the fineness of coal using a BoxBehnken design. Table 2 shows the experimental design matrix with coded and actual values of parameters A, B, and $\mathrm{C}$.

To find the optimum conditions, a quadratic model is used to relate fineness of coal to independent parameters. This model can be written as:

$y=\alpha_{0}+\sum_{j=1}^{n} \alpha_{j} x_{j}+\sum_{j=1}^{n} \alpha_{j j} x_{j}^{2}+\sum_{j=1}^{n-1} \sum_{k=2}^{n} \alpha_{j k} x_{j} x_{k}+\delta$

The set of regression coefficients $\alpha$ 's are unknown and estimated by least squares. In vector-matrix, the equation for least square fit is given by:

$Y=X \alpha+\delta$

where $Y$ is defined as the measured values and $\mathrm{X}$ to be a matrix of independent variables. Regression coefficients $\alpha$

Table 2 The level of variables in Box-Behnken design

\begin{tabular}{lccc}
\hline Parameter & Low $(-1)$ & Center $(0)$ & High $(+1)$ \\
\hline A (Grinding time) & 4 & 6 & 8 \\
B (Number of balls) & 10 & 15 & 20 \\
C (Amount of feed) & 100 & 150 & 200 \\
\hline
\end{tabular}


is solved by premultiplying by the non singular regression matrix transpose $X^{\prime}$

$\beta=\left(X^{\prime} X\right)^{-1} X^{\prime} Y$

where $X^{\prime}$ is the transpose of the matrix $X$ and $\left(X^{\prime} X\right)^{-1}$ is the inverse of the matrix $X^{\prime} X$. Applying the present variables in Eq. (2), the equation will expand in the form as follows:

$$
\begin{aligned}
y_{d_{80}}= & \alpha_{0}+\alpha_{1} A+\alpha_{2} B+\alpha_{3} C+\alpha_{4} A B+\alpha_{5} A C+\alpha_{6} B C \\
& +\alpha_{7} A^{2}+\alpha_{8} B^{2}+\alpha_{9} C^{2}+\delta_{i}
\end{aligned}
$$

where $y$ is response (fineness of coal of $80 \%$ passing), and $A, B$, and $C$ are the independent parameters. $\alpha_{0}$ is the constant coefficient, $\alpha_{1}, \alpha_{2}$, and $\alpha_{3}$, are the coefficients for linear effect, $\alpha_{4}, \alpha_{5}$, and $\alpha_{6}$, are the coefficients for interaction effect, $\alpha_{7}, \alpha_{8}$, and $\alpha_{9}$, are the coefficients for quadratic effect, and $\delta_{i}$ is the error.

Response surface methodology uses the experimental data points of the design matrix to a proposed model and the unknown coefficients. To find the minimum number of experimental run required for Box-Benhken design one can use equation given below:

$N=2 N_{f}\left(N_{f}-1\right)+C_{p}$

where $N_{f}$ is the number of parameters used to fit the model, and $C_{p}$ is the number of the central points. To evaluate the coefficient values 15 experiments were carried out for each particle size and total 45 experiments were done for three different particle size according to the Box-Behnken design. Figure 1 shows the distribution of the experimental data points in the graphical form. Accordingly experiments were designed and Table 3 shows the design matrix of the experiments for three different particle sizes.

\section{Result and discussion}

There were 15 experiments which were done for each coal particle size as listed in Table 4. Model equations basically represent the relationship between fineness as $d_{80}$ and
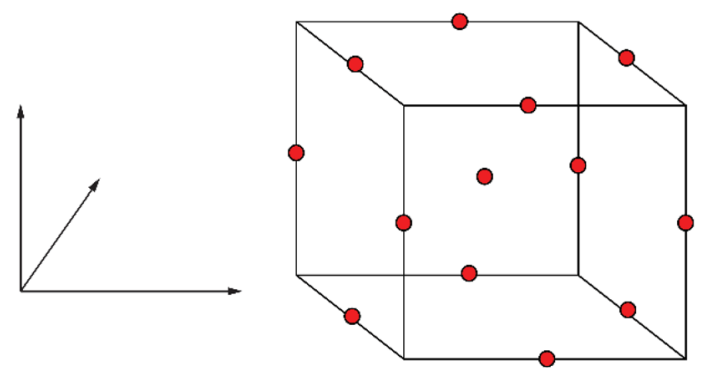

Fig. 1 The graphical representation of a three parameters BoxBehnken design
Table 3 Design matrix with coded and actual design parameters

\begin{tabular}{lrrrrrrr}
\hline Run no. & \multicolumn{2}{c}{ Coded values } & & \multicolumn{3}{c}{ Actual values } \\
\cline { 2 - 3 } \cline { 6 - 7 } & A & B & C & & A & B & C \\
\hline 1 & +1 & 0 & -1 & 8 & 15 & 100 \\
2 & 0 & +1 & +1 & 6 & 20 & 200 \\
3 & +1 & -1 & 0 & 8 & 10 & 150 \\
4 & -1 & 0 & -1 & 4 & 15 & 100 \\
5 & -1 & +1 & 0 & 4 & 20 & 150 \\
6 & 0 & 0 & 0 & 6 & 15 & 150 \\
7 & +1 & +1 & 0 & 8 & 20 & 150 \\
8 & 0 & -1 & -1 & 6 & 10 & 100 \\
9 & -1 & 0 & +1 & 4 & 15 & 200 \\
10 & 0 & 0 & 0 & 6 & 15 & 150 \\
11 & -1 & -1 & 0 & 4 & 10 & 150 \\
12 & +1 & 0 & +1 & 8 & 15 & 200 \\
13 & 0 & -1 & +1 & 6 & 10 & 200 \\
14 & 0 & 0 & 0 & 6 & 15 & 150 \\
15 & 0 & +1 & -1 & 6 & 20 & 100 \\
\hline
\end{tabular}

different experimental design parameters. For three different size fractions of coal using Box-Behnken design were obtained as given below:

For $-1.65+4 \mathrm{~mm}$ size fraction:

$$
\begin{aligned}
y 1_{d_{80}=} & 781.25+9.375 A+43.12 B+12.43 C+3.12 A B \\
& -0.4375 A C-4.34 \times 10^{-16} B C-3.12 A^{2} \\
& -2.75 B^{2}-0.0225 C^{2}
\end{aligned}
$$

For $-0.7+1 \mathrm{~mm}$ size fraction:

$$
\begin{aligned}
y 2_{d_{80}}= & -30+72.5 A+44 B+5.27 C-2.25 A B-0.1 A C \\
& +7 \times 10^{-2} B C-3.43 A^{2}-1.65 B^{2}-0.0145 C^{2}
\end{aligned}
$$

For $-0.25+0.65 \mathrm{~mm}$ size fraction:

$$
\begin{aligned}
y 3_{d_{80}}= & 295.62-39.68 A+1.12 B+1.67 C-0.37 A B \\
& -0 A C+0 B C+2.65 A^{2}-0.075 B^{2}-0.002 C^{2}
\end{aligned}
$$

Using the parameters defined in Table 2, the experimental values were obtained by performing experiments and the predicted values were calculated using Eqs. (7-9) in Table 3. From the experimental results listed in Table 4 and Eq. (5), the second order response functions representing $\mathrm{d}_{80}$ can be expressed in model equations. Table 5 shows the validation of model developed by using BoxBehnken design with experimental values of three different size fractions. The responses of three different size fraction of fineness can be calculated by Eqs. (7-9) for different variables defined. 
Table 4 Actual and coded values of three parameters for three responses

\begin{tabular}{|c|c|c|c|c|c|c|}
\hline \multirow[b]{2}{*}{ Run no. } & \multicolumn{3}{|c|}{ Parameter } & \multicolumn{3}{|c|}{ Experimental values of responses } \\
\hline & $\mathrm{A}(\min )$ & B & $C(g)$ & $\boldsymbol{y} 1_{\boldsymbol{d}_{80}}(\mu \mathrm{m})$ & $\boldsymbol{y} 2_{\boldsymbol{d}_{80}}(\mu \mathrm{m})$ & $\boldsymbol{y} 3_{\boldsymbol{d}_{80}}(\mu \mathrm{m})$ \\
\hline 1 & $8(+1)$ & $15(0)$ & $100(-1)$ & 1700 & 770 & 250 \\
\hline 2 & $6(0)$ & $20(+1)$ & $200(+1)$ & 1900 & 880 & 350 \\
\hline 3 & $8(+1)$ & $10(-1)$ & $150(0)$ & 1900 & 875 & 325 \\
\hline 4 & $4(-1)$ & $15(0)$ & $100(-1)$ & 1800 & 800 & 300 \\
\hline 5 & $4(-1)$ & $20(+1)$ & $150(0)$ & 1875 & 860 & 340 \\
\hline 6 & $6(0)$ & $15(0)$ & $150(0)$ & 2000 & 900 & 320 \\
\hline 7 & $8(+1)$ & $20(+1)$ & $150(0)$ & 1750 & 725 & 275 \\
\hline 8 & $6(0)$ & $10(-1)$ & $100(-1)$ & 1850 & 800 & 275 \\
\hline 9 & $4(-1)$ & $15(0)$ & $200(+1)$ & 2250 & 950 & 400 \\
\hline 10 & $6(0)$ & $15(0)$ & $150(0)$ & 2000 & 900 & 320 \\
\hline 11 & $4(-1)$ & $10(-1)$ & $150(0)$ & 2150 & 920 & 375 \\
\hline 12 & $8(+1)$ & $15(0)$ & $200(+1)$ & 1975 & 880 & 350 \\
\hline 13 & $6(0)$ & $10(-1)$ & $200(+1)$ & 2100 & 910 & 375 \\
\hline 14 & $6(0)$ & $15(0)$ & $150(0)$ & 2000 & 900 & 320 \\
\hline 15 & $6(0)$ & $20(+1)$ & $100(-1)$ & 1650 & 700 & 250 \\
\hline
\end{tabular}

Table 5 Comparison of experimental and predicted $d_{80}$ values

\begin{tabular}{|c|c|c|c|c|c|}
\hline \multicolumn{2}{|l|}{$\boldsymbol{y} 1_{\boldsymbol{d}_{80}}(\mu \mathrm{m})$} & \multicolumn{2}{|l|}{$\boldsymbol{y} 2_{\boldsymbol{d}_{80}}(\mu \mathrm{m})$} & \multicolumn{2}{|l|}{$\boldsymbol{y} 3_{\boldsymbol{d}_{80}}(\mu \mathrm{m})$} \\
\hline Experimental & Predicted & Experimental & Predicted & Experimental & Predicted \\
\hline 1700 & 1728 & 770 & 756 & 250 & 250 \\
\hline 1900 & 1925 & 880 & 866 & 350 & 355 \\
\hline 1900 & 1896 & 875 & 875 & 325 & 328 \\
\hline 1800 & 1828 & 800 & 806 & 300 & 304 \\
\hline 1875 & 1878 & 860 & 860 & 340 & 348 \\
\hline 2000 & 2000 & 900 & 900 & 320 & 325 \\
\hline 1750 & 1753 & 725 & 745 & 275 & 286 \\
\hline 1850 & 1825 & 800 & 813 & 275 & 281 \\
\hline 2250 & 2221 & 950 & 963 & 400 & 411 \\
\hline 2000 & 2000 & 900 & 900 & 320 & 325 \\
\hline 2150 & 2146 & 920 & 900 & 375 & 374 \\
\hline 1975 & 1946 & 880 & 873 & 350 & 358 \\
\hline 2100 & 2131 & 910 & 916 & 375 & 389 \\
\hline 2000 & 2000 & 900 & 900 & 320 & 325 \\
\hline 1650 & 1618 & 700 & 693 & 250 & 248 \\
\hline
\end{tabular}

The actual and predicted values of three different size fractions are depicted in Figs. 2, 3 and 4. Predicted values are quite close to the experimental values and the values of $R^{2}$ are $0.98,0.97$ and 0.99 for $-1.65+4 \mathrm{~mm}$ size fraction, $-0.7+1 \mathrm{~mm}$ size fraction and $-0.25+0.65 \mathrm{~mm}$ size fraction, respectively.

In order to understand the effect of operating parameters on the $\mathrm{d}_{80}$ the results are shown in Figs. 5, 6, 7, 8, 9, 10, 11, 12 and 13. Figures 5, 6 and 7 show the 3D response surface plot for coarse size fraction $(-1.65+4 \mathrm{~mm})$. Figure 5 shows the effect of number of balls and grinding time on fineness. The grinding time and the number of balls on the coarse particle size have positive effect as the increased grinding time and increased number of balls enhance the fineness. However, individual effect of balls can also be observed as for less time increasing number of balls results in increased fineness. Figure 6 shows the effect of number of balls and amount of feed on response. The decreased 


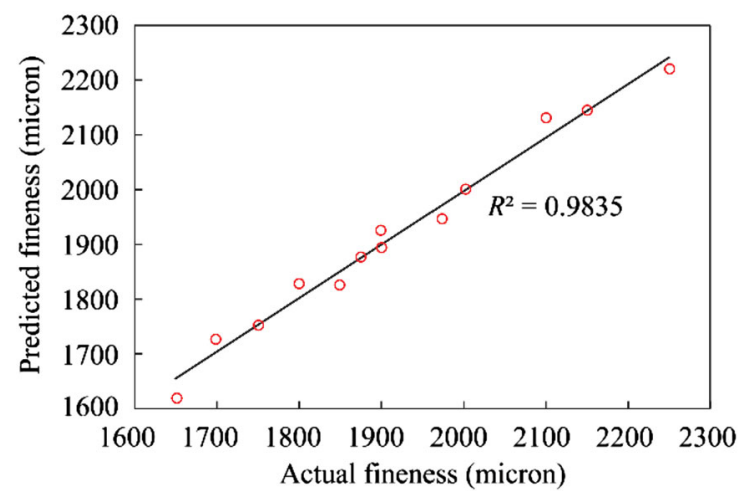

Fig. 2 Experimental values versus predicted values of fineness for size fraction for $-1.65+4 \mathrm{~mm}$ size fraction

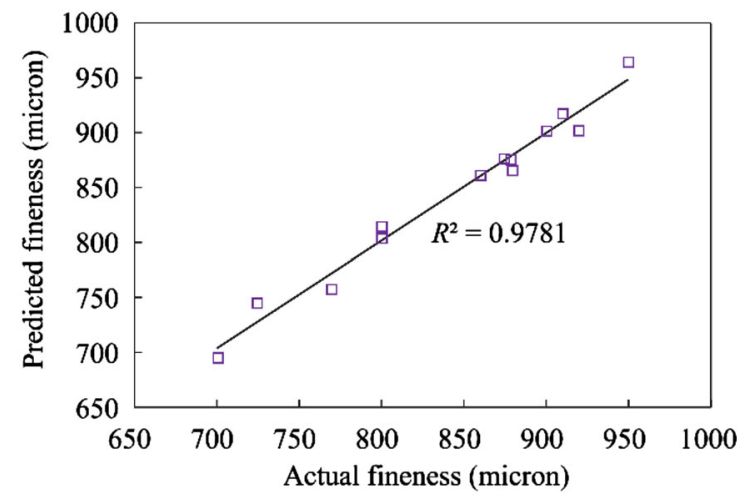

Fig. 3 Experimental values versus predicted values of fineness for size fraction for $-0.7+1 \mathrm{~mm}$ size fraction

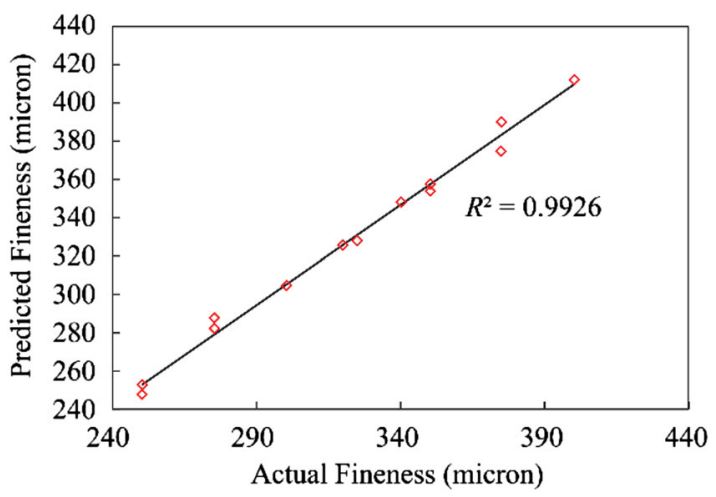

Fig. 4 Experimental values versus predicted values of fineness for size fraction for $-0.25+0.65 \mathrm{~mm}$ size fraction

amount of feed and increased number of balls are in favor of fineness. Figure 7 shows the effect of grinding time and amount of feed. It is revealed that increasing grinding time and decreasing amount of feed produces fine material.

Figures 8,9 and 10 show the effect of different parameters on response in contour plot for the $-0.7+1 \mathrm{~mm}$ size fraction. Figure 8 shows that decrease

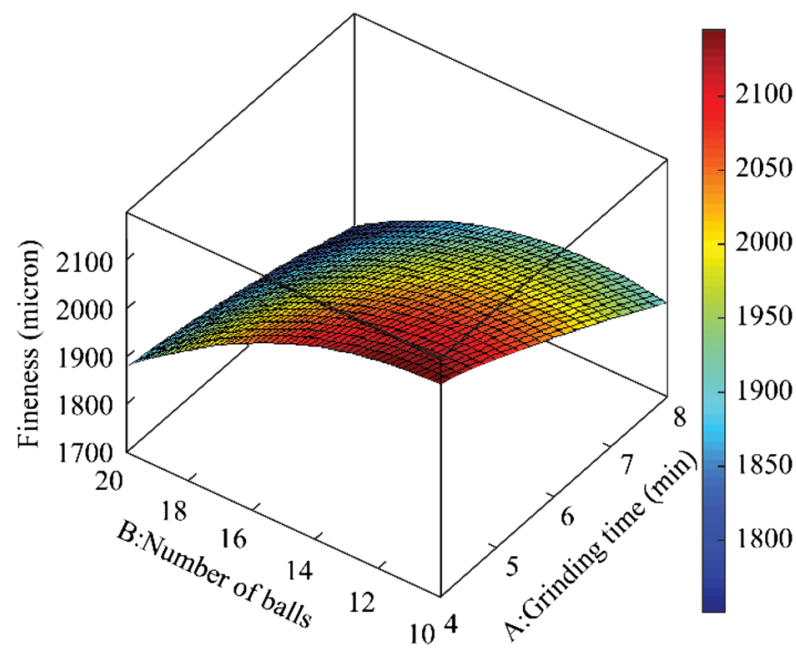

Fig. 5 Response surface of fineness of coal to the variation of number of balls and grinding time at average amount of feed of 150 $\mathrm{gm}$ for $-1.65+4 \mathrm{~mm}$ size fraction

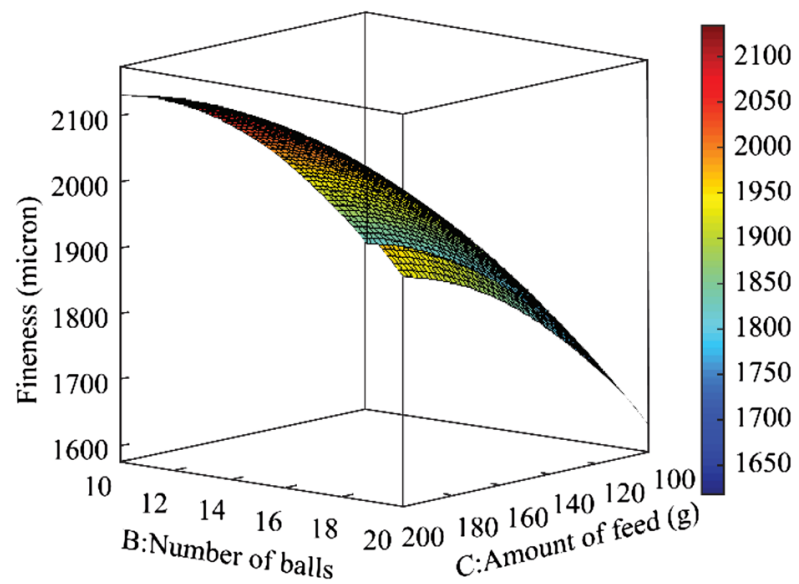

Fig. 6 Response surface of fineness of coal to the variation of number of balls and amount of feed at average grinding time of $6 \mathrm{~min}$ for $-1.65+4 \mathrm{~mm}$ size fraction

in amount of feed and increase in grinding time more fine material can be produced. This may be due to more impact of balls will be observed by the feed which results in more fine material. Figure 9 shows that number of balls used in grinding plays an important role. Increasing number of balls can produce finer particles. On the other hand if the fineness is fixed one can reduce the grinding time and energy can be saved. Figure 10 shows the effect of number of balls and grinding time on $\mathrm{d}_{80}$. It is clear from figure that number of balls on fineness has dominant effect than grinding time. With more number of balls and less grinding time one can produce more fine powder. The figure reflects that process will be inefficient if ball mill is operated between 11 and 16 number of balls and 4 to $5.9 \mathrm{~min}$ grinding time. 


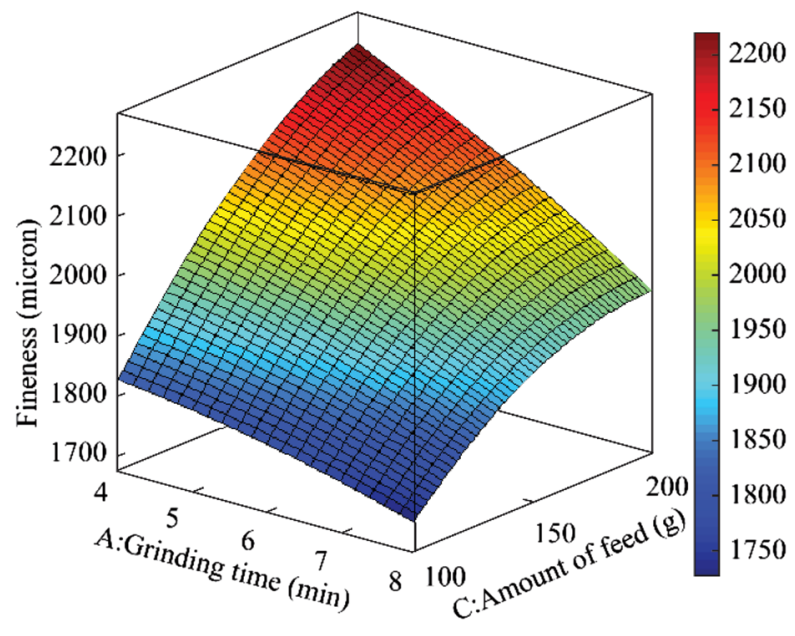

Fig. 7 Response surface of fineness of coal to the variation of grinding time and amount of feed at average number of balls of 15 for $-1.65+4 \mathrm{~mm}$ size fraction

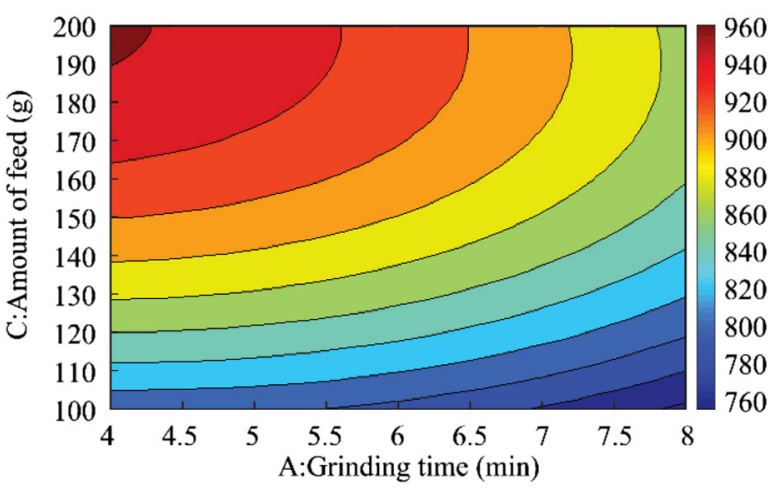

Fig. 8 Contour plot response surface of fineness of coal to the variation of grinding time and amount of feed at average number of balls of 15 for $-0.7+1 \mathrm{~mm}$ size fraction

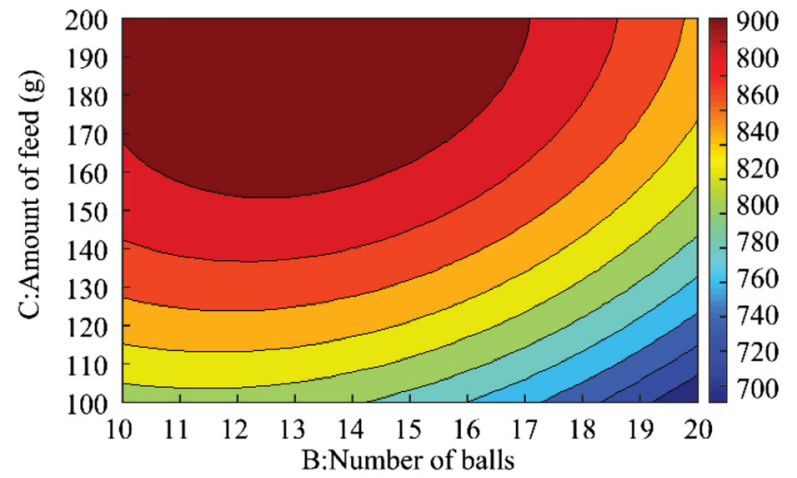

Fig. 9 Contour plot response surface of fineness of coal to the variation of number of balls and amount of feed at average grinding time of $6 \mathrm{~min}$ for $-0.7+1 \mathrm{~mm}$ size fraction

Figures 11, 12 and 13 show the contour and 3D surface plot response of $-0.25+0.65 \mathrm{~mm}$ size fraction. These figures show the similar effect of number of balls, amount

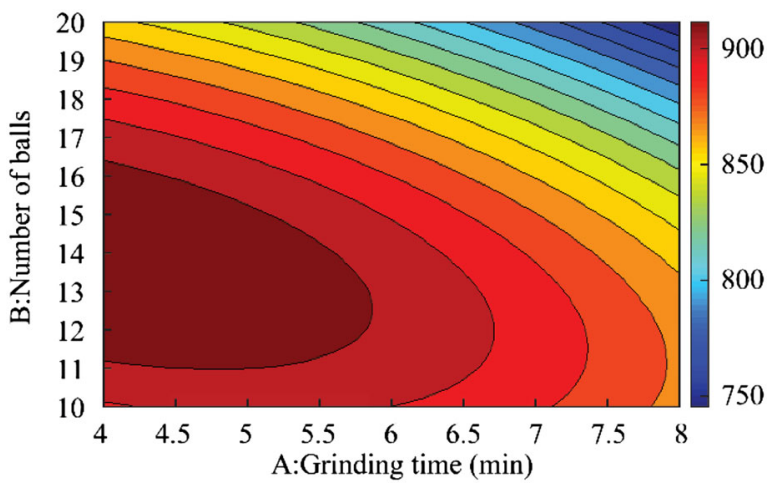

Fig. 10 Contour plot response surface of fineness of coal to the variation of number of balls and grinding time at average amount of feed of $150 \mathrm{gm}$ for $-0.7+1 \mathrm{~mm}$ size fraction

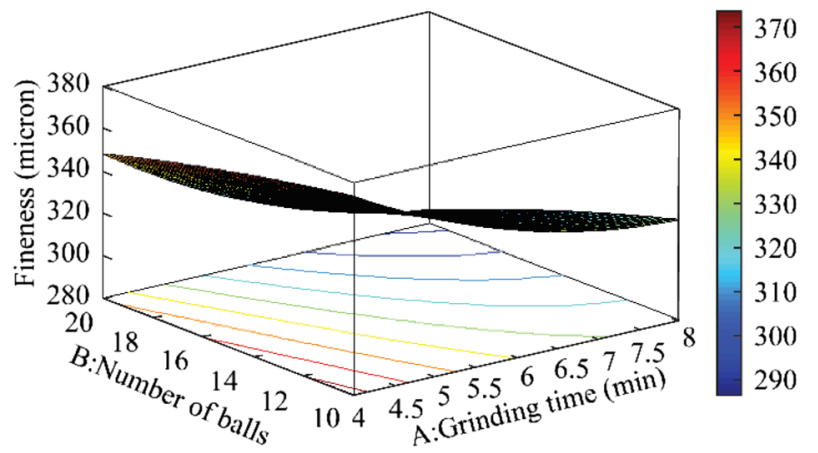

Fig. 11 Contour and surface plot of response surface of fineness of coal to the variation of number of balls and grinding time at average amount of feed of $150 \mathrm{gm}$ for $-0.25+0.65 \mathrm{~mm}$ size fraction

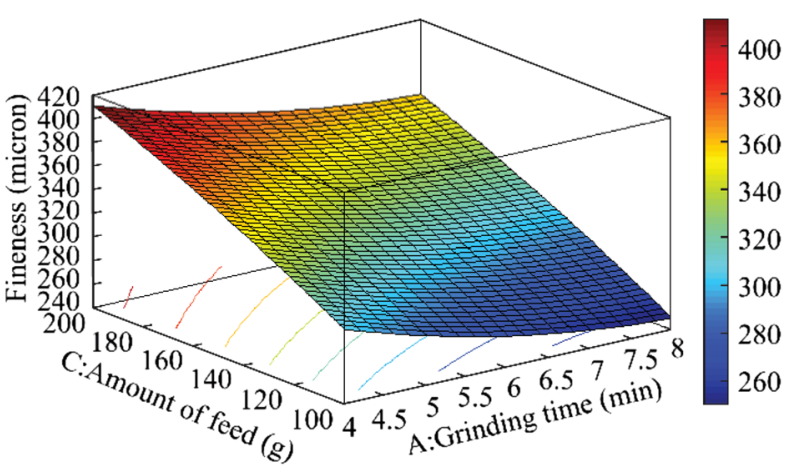

Fig. 12 Contour and surface plot of response surface of fineness of coal to the variation of number of balls and amount of feed at average grinding time of $6 \mathrm{~min}$ for $-0.25+0.65 \mathrm{~mm}$ size fraction

of feed and grinding time on fineness as discussed for the other two size fractions. These contour plots can help finding fineness of coal particles at any zone of the experimental region. The results concludes that the small amount of feed stayed longer will result in fine product. 


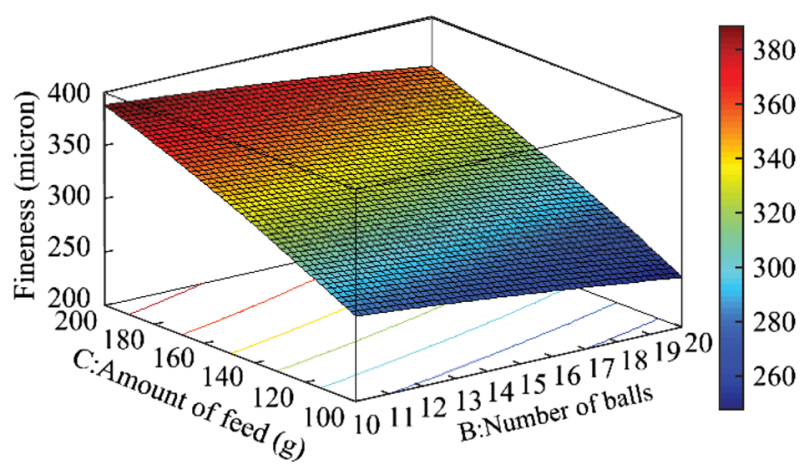

Fig. 13 Contour and surface plot of response surface of fineness of coal to the variation of grinding time and amount of feed at average number of balls of 15 for $-0.25+0.65 \mathrm{~mm}$ size fraction

The optimal levels of different parameters studied like number of balls, grinding time, and amount of feed could provide a beneficial information to calculate the power requirement to grind a particular amount of coal. The response surface methodology provides a relationship among the parameters which can be utilized in finding optimal values.

\section{Conclusions}

In the present work, the application of response surface methodology (Box-Behnken design) for grinding of Indian coal of three different size fractions had been discussed. The three level factorial Box-Behnken experimental design model was investigated for three variables namely: grinding time, ball charge and amount of feed used for grinding of Indian coal. The three different model equations were obtained for three different size fractions of coal. MATLAB 7.1 software was used to model the equations. Predicted values of $\mathrm{d}_{80}$ for three different sizes were in good agreement with the experimental results in the range of $R^{2}$ value of $0.97-0.99$. The model graphs were shown in 3D surface plots, contour plots as well as combination of contour and 3D surface plots were also drawn for better understanding. This study confirms that BoxBehnken design with response surface methodology can be applied for the grinding test of different size fraction of Indian coal. This technique is fast and efficient to show the final results of experiments and fewer number of experiments are required to extract the complex information of the system. Using surface response technique one can find optimum conditions for grinding of coal efficiently. This paper shows that this technique is economical as well as less time consuming.

\section{Compliance with ethical standards}

Conflict of interest We confirm that none of the authors has any competing interest related to this manuscript.

Open Access This article is distributed under the terms of the Creative Commons Attribution 4.0 International License (http://crea tivecommons.org/licenses/by/4.0/), which permits unrestricted use, distribution, and reproduction in any medium, provided you give appropriate credit to the original author(s) and the source, provide a link to the Creative Commons license, and indicate if changes were made.

\section{References}

Aslan N, Cebeci Y (2007) Application of Box-Behnken design and response surface methodology for modeling of some Turkish coals. Fuels 86:90-97

Barranco R, Colechin M, Cloke M, Gibb W, Lester E (2006) The effects of grind quality on coal burnout in a $1 \mathrm{MW}$ combustion test facility. Fuel 85:1111-1116

Edadnejad A, Karimi GR, Dehghani H (2013) Application of Response Surface methodology for modeling of ball mills in copper sulphide ore grinding. Powder Technol 245:292-296

Gunaraj V, Murugan N (1999) Application of response surface methodologies for predicting weld base quality in submerged arc welding of pipes. J Mater Process Technol 88:266-275

Harrison PC, Rowson N (1997) In: Proceedings of the 1997 Jubliee Research Event, Institution of Chemical Engineers, Nottingham, UK

Jankovic A (2001) Media stress intensity analysis for vertical stirred mills. Miner Eng 14(10):1177-1186

Kincl M, Turk S, Vrecer F (2005) Application of experimental design methodology in development and optimization of drug release method. Int J Pharam 291:39-49

Kwak JS (2005) Application of Taguchi and surface response surface methodologies for geometric error in surface grinding process. Int J Mach Tools Manuf 45:327-334

Lester E, Kingman S, Dodds C (2005) Increased coal grindability as a result of microwave pretreatment at economic energy inputs. Fuel 84:423-427

Prasher CL (1987) Crushing and Grinding Process Handbook. Wiley, Chichester

Tuzun MA (1994) A study of comminution in a vertical stirred ball mill, PhD Desertation. Chemical Engineering Department, University of Natal 